\title{
Combining Ability and Gene Action Estimates of Eight Parent Diallel Crosses of Chickpea for Ascochyta Blight
}

\author{
Mohamed Labdi, ${ }^{1}$ Samia Ghomari, ${ }^{2}$ and Samia Hamdi ${ }^{1}$ \\ ${ }^{1}$ INRA-ALGERIA, 22000 Sidi Bel Abbès, Algeria \\ ${ }^{2}$ Université Djillali Liabès, 22000 Sidi Bel Abbès, Algeria \\ Correspondence should be addressed to Mohamed Labdi; mohamedmlabdi@gmail.com
}

Received 30 September 2014; Accepted 17 December 2014

Academic Editor: Gábor Kocsy

Copyright (C) 2015 Mohamed Labdi et al. This is an open access article distributed under the Creative Commons Attribution License, which permits unrestricted use, distribution, and reproduction in any medium, provided the original work is properly cited.

Ascochyta blight resistance was studied in half-diallel cross involving eight genotypes of chickpea at seedling and adult stages. The disease was rated in the greenhouse with a modified scale from 0 to 100\%. The diallel analysis was performed on $28 \mathrm{~F} 1$ and their F2. The results were analyzed with the Hayman and Griffing methods. The general combining ability is most important for two generations, is highly significant for the two stages, and is more important than specific combining ability. This result reflects a strong preponderance of additive effects and epistasis additive $\times$ additive with respect to dominance effects in this material for the two generations, which shows the predominance of additive versus dominance. Estimates of heritability are very high. The additive effects have the highest value indicating the importance of this component for resistance to Ascochyta. For seedling stage, the negative sign of $\mathrm{F}$ for both generations indicates that there are much more recessive alleles that affect resistance to the disease. In adult stage, $\mathrm{F}$ is positive in both generations and shows more dominant alleles that control plant reaction to pathogen. $\mathrm{H}^{2}$ is positive in both generations which show that dominant genes are acting mostly towards the susceptibility.

\section{Introduction}

Ascochyta blight caused by Ascochyta rabiei (Pass.) Labr. is a devastating disease of chickpea (Cicer arietinum L.) in most of the chickpea-producing countries in the Mediterranean region. In Algeria when the conditions are favorable for the development of the disease, the yield is decreasing drastically (10 to $80 \%$ of losses). Sometimes it may cause failure of the whole chickpea crop. The fungus attack all above ground parts of the plant causes necrotic lesions and causes a breakage of branches. The disease perpetuates through infected seed and crop debris [1].

Even though many cultivars are taught to be resistant, they become susceptible. The evolution of new pathotypes or more aggressive forms is frequently invoked to explain such outbreaks. Current cultivars only possess partial resistance to the pathogen and this level of resistance can breakdown easily because the pathogen is highly variable due to its potential for sexual recombination. Sexual stage is reached by Didymella rabiei which is a heterothallic fungus that requires two mating types [2]. The sexual stage has been observed in chickpea field at Sidi Bel Abbès region in 1997.

The genetics of resistance was studied with many authors; some confirmed the nature of monogenic form of resistance, dominant or recessive gene [3], and others the involvement of more than one gene or many partials dominant genes conferring resistance to Ascochyta blight [4].

Recent studies suggest that several QTLs are involved in controlling resistance to Ascochyta blight. The major QTLs generally showed additive gene action, as well as dominance interlocus interaction in the multiple genetic models [5].

Diallel cross studies have shown good GCA effects for various quantitative traits. The crosses made can be used as good yielding chickpea genotypes heaving resistance against A. rabiei [6]. The absence of gene interactions and the presence of additive effects lead to the possibility of enhancing the level of resistance to $M$. pinodes by gene pyramiding. The analysis performed revealed that the dominance component was also important in the control of resistance [4]. 
The specific objective of this study was to evaluate the relative importance of general and specific combining ability and the genetic components for resistance to Ascochyta rabiei. Also a graphical analysis according to Reddy et al. [7] was performed.

\section{Materials and Methods}

Eight chickpea lines, ILC 263, ILC 605, ILC 200, ILC 7374, ILC 7795, ILC 8068, ICC 4475, and ICC 12004 from ICARDA, were crossed in all possible combinations, excluding the reciprocals. This half diallel of $28 \mathrm{~F} 1$ and their $\mathrm{F} 2$ were planted in the green house. The seeds of this plant material were divided into two lots. One concerns the plants inoculated at the reproduction stage (adult-diallel) and the other, the plants inoculated at the seedling stage (seedling-diallel). Seeds of each diallel were sown in a lattice arrangement, each comprising two repetitions and 8 randomized blocks. The seeds of both diallel crosses were planted, in pot $(26 \mathrm{~cm})$ with four seeds per pot and per line and with one susceptible (IL 263) in the middle of the pot. The seeds of the seedlingdiallel were planted when the adult-diallel plants had reached the full flowering or early pod formation. Pots of adultdiallel were laid down on the ground covered with a sheet of plastic in the greenhouse. In contrast, the seedling-diallel pots were placed on benches in the same greenhouse. The plants received a complete foliar fertilization once a week, from 5-leaf stage to full bloom stage. All plants were irrigated lightly every two days. Inoculation of plants for both diallels was performed with race 4 with a suspension of $5 \times 10^{5}$ spores $/ \mathrm{mL}$. with a knapsack sprayer when plants of seedlingdiallel were aged of ten days. After that, the plants have been recovered with a sheet of plastic for seven days. The excess of temperature occurred sometimes in midday $\left(24\right.$ to $26^{\circ} \mathrm{C}$ and exceptionally $30^{\circ} \mathrm{C}$ ); it was frequently limited by spraying the greenhouse for a few minutes and creating an air flow.

For both diallels, the disease was visually assessed 21 days after inoculation. One modified scale of Reddy et al. [7] for disease reading was used, expressed by percentages of necrosis on stem and breakage of the branches (0 to 100\%) (Table 1).

For each cross, an average of 30 plants for each parent, 26 plants for F1 and 90 plants for the F2, were analyzed. In this study, the diallel analysis was performed using a program written in two parts by Dr. Murari Singh at ICARDA, based on the methods of Hayman and Griffing and according to the procedure of Singh and Chaudhary (1979).

The objective of this study is to obtain information on

(i) nature of the importance of genetic parameters,

(ii) the general and specific combining ability of parents and their crosses.

The first part gives an assessment of the additive and dominance effects. It also helps to define the type of allele involved in the control of the character studied (Hayman approach). The second part breaks down the genetic variance in component estimates and more particularly values of the general and specific combining ability of lines used in this
TABLE 1: Modified scale of Reddy et al. [7] for disease reading.

\begin{tabular}{lcc}
\hline Notation \% & Branches and stem broken & Type of lesion \\
\hline 0 & 0 & \\
10 & 0 & $0-2 \mathrm{~mm}$ \\
20 & 0 & $2-4 \mathrm{~mm}$ \\
30 & 0 & $4-6 \mathrm{~mm}$ \\
40 & 0 & $6-8 \mathrm{~mm}$ \\
50 & 40 & " \\
$60-70$ & 50 & " \\
$70-80$ & $60-70$ & \\
$80-90$ & $70-100$ & \\
100 & Destroyed plant & \\
\hline
\end{tabular}

study (Griffing approach). Diallel analysis according to the method of Hayman [8] is based primarily on a model where the additive and dominance are prevalent. However, we shall note that we have made change concerning our data (\% of disease severity) in Arc sinus because, in general, a change of scale may remove or reduce the variance due to the interaction [8].

\section{Results}

Tables 2 to 3 show the average values of the intensity of the disease by combination and by generation. The ratings of parents F1 and F2 were done on the same experiment and in the same time. Disease ratings of tested material increased from the resistant to the susceptible one, indicating that the conditions of inoculation, incubation, and latency were optimal.

The classification of parental lines regarding reaction to Ascochyta rabiei is different between the two stages (Table 4).

(1) For the seedling stage the lines are divided into three groups significantly different:

(i) susceptible lines: ILC 263 and ILC 605,

(ii) moderately susceptible line: ICC 12004,

(iii) resistant lines: ILC 8068, ICC 4475, ILC 200, ILC 7374, and ILC 7795.

(2) For the adult stage, the lines are divided only in two different groups:

(i) susceptible lines: ICC 12004, ILC 263, ILC 605, and ICC 4475 ,

(ii) resistant lines: ILC 8068, ILC 7374, ILC 7795, and ILC 200.

It appears that the lines ICC 12004 and ICC 4475 are moderately susceptible to resistant in the seedling stage and became completely susceptible in the adult stage. 
TABLE 2: Mean value of disease severity of chickpea inoculated by Ascochyta rabiei in a diallel cross at the seedling stage for the F1 generation above the underlined data and the F2 generation below the underlined data.

\begin{tabular}{lcccccccc}
\hline Line & ILC & ILC & ILC & ICC & ILC & ILC & ILC & ILC \\
& 200 & 263 & 605 & 4475 & 8068 & 7374 & 7795 & 7795 \\
\hline ILC 200 & 41.26 & 73.41 & 50.01 & 44.08 & 39.54 & 33.04 & 33.24 & 40.18 \\
ILC 263 & $\underline{59.13}$ & 78.74 & 80.66 & 68.61 & 68.25 & 57.67 & 54.50 & 66.44 \\
ILC 605 & 44.46 & $\underline{77.91}$ & 76.82 & 52.56 & 58.12 & 45.36 & 47.92 & 56.85 \\
ICC 4475 & 45.84 & 69.07 & $\underline{62.65}$ & 43.84 & 43.94 & 39.36 & 40.63 & 61.12 \\
ILC 8068 & 43.24 & 65.70 & 66.06 & $\underline{48.83}$ & 45.99 & 39.84 & 40.01 & 43.86 \\
ILC 7374 & 38.26 & 50.47 & 53.92 & 37.78 & $\underline{39.90}$ & 36.05 & 38.35 & 45.10 \\
ILC 7795 & 35.47 & 61.84 & 50.65 & 39.54 & 40.85 & $\underline{35.56}$ & 33.00 & 44.50 \\
ILC 12004 & 37.51 & 63.94 & 50.91 & 45.80 & 35.09 & 33.00 & $\underline{51.87}$ & 51.87 \\
\hline
\end{tabular}

TABLE 3: Mean value of disease severity of chickpea inoculated by Ascochyta rabiei in a diallel cross at the adult stage for the F1 generation above the underlined data and the F2 generation below the underlined data.

\begin{tabular}{lcccccccc}
\hline Line & ILC & ILC & ILC & ICC & ILC & ILC & ILC & ILC \\
& 200 & 263 & 605 & 4475 & 8068 & 7374 & 7795 & 7795 \\
\hline ILC 200 & 38.75 & 79.07 & 66.37 & 72.22 & 61.96 & 52.00 & 44.68 & 79.12 \\
ILC 263 & $\underline{71.08}$ & 84.48 & 85.06 & 83.20 & 84.16 & 73.83 & 66.93 & 81.14 \\
ILC 605 & 65.94 & $\underline{84.23}$ & 81.88 & 85.97 & 73.74 & 63.53 & 67.35 & 84.86 \\
ICC 4475 & 78.83 & 84.09 & $\underline{82.07}$ & 83.72 & 79.59 & 68.30 & 79.88 & 81.43 \\
ILC 8068 & 54.97 & 79.65 & 77.30 & $\underline{75.91}$ & 52.46 & 53.47 & 50.47 & 79.02 \\
ILC 7374 & 61.44 & 73.78 & 68.98 & 65.97 & $\underline{60.53}$ & 45.47 & 41.47 & 72.41 \\
ILC 7795 & 48.18 & 69.27 & 63.29 & 78.08 & 62.22 & $\underline{49.62}$ & 38.78 & 70.13 \\
ILC 12004 & 67.32 & 82.73 & 78.29 & 83.11 & 70.60 & 78.80 & $\underline{74.13}$ & 84.58 \\
\hline
\end{tabular}

\subsection{Estimate of the Combining Ability of Griffing}

3.1.1. Seedling Stage. Diallel analysis provides information about the combining ability of genotypes and the effect of genes on inheritance of traits. This measure of general combining ability (GCA) gives information on the average of behavior of parents as well as about the expression of additive gene effects. In addition, the effects of nonadditive genes are indicated by specific combining ability (SCA).

The analysis of variance indicates a general combining ability (GCA) more important than specific combining ability (SCA) which is not significant for generations F1 and F2 (Tables 5 and 6). The estimated values of the GCA give three groups of lines significantly different (Table 7).

(i) ILC 263 and ILC 605 are the most sensitive and their GCA is positive. These lines are significantly different and have important gametic effects and mark strongly theirs offspring in the direction of susceptibility.

(ii) ILC 8068, ICC 4475, and ICC12004 are moderately sensitive parents. Their estimated values are not significant. However, the value of ICC 12004 in F2 is significant and this line is close to the next group.

(iii) The most resistant lines ILC 200, ILC 7374, and ILC 7795 have their values significant and negative.

The estimates of "variances" GCA $\left(\alpha^{2} \mathrm{~g}\right)$ and SCA $\left(\alpha^{2} \mathrm{gs}\right)$ decrease only very slightly between the F1 and F2 (Table 8 ).
The value of GCA $\left(\alpha^{2} \mathrm{~g}\right) / \mathrm{SCA}\left(\alpha^{2} \mathrm{gs}\right)$ ratio is 10 for F1 and 15 for F2, which demonstrate that GCA variance was higher than SCA variance component for Ascochyta rabiei resistance. Variability for GCA suggested that genetic gain is achievable through selection over the segregating population.

The decomposition of genetic variances in variance due to additive effect $\left(\alpha^{2} \mathrm{~A}\right)$ and the dominance $\left(\alpha^{2} \mathrm{D}\right)$ gives high values for the first component in a ratio of 20 to 1 in $\mathrm{F} 1$ and 30 to 1 in F2. This result reflects a strong preponderance of additive effects and epistasis additive $\times$ additive with respect to dominance effects in this material for the two generations. The values obtained of heritability are very high (Table 9), either in the narrow sense $\left(\mathrm{h}_{2} \mathrm{~s}=0.87\right.$ in F1 and 0.71 in F2) or in a broad sense $\left(h_{2} I=0.91\right.$ for F1). Heritability values were high indicating that improvement of this character seemed to be genetically reliable.

3.1.2. Adult Stage. The results of the analysis of the general combining ability (GCA) for F1 and F2 are given in Table 10 . The general combining ability (GCA) is by far the most important for two generations and is highly significant. The analysis of parental effects (GCA) identifies three groups significantly different (Table 11).

(i) A first group of four breeding lines is clearly distinguishable from the others with estimated values of GCA of 9.95 to 9.44 for F1 and 9.04 to 5.87 for F2; these values are significantly different from zero for the two 
TABLE 4: Ranking of chickpea lines to Ascochyta blight.

\begin{tabular}{|c|c|c|c|}
\hline \multicolumn{2}{|c|}{ Seedling stage } & \multicolumn{2}{|c|}{ Adult stage } \\
\hline Line & $\%$ disease severity & Line & $\%$ disease severity \\
\hline ILC 263 & $78.74^{\mathrm{a}}$ & ICC 12004 & $84.58^{\mathrm{a}}$ \\
\hline \multirow[t]{2}{*}{ ILC 605} & $76.82^{\mathrm{a}}$ & ILC 263 & $84.48^{\mathrm{a}}$ \\
\hline & & ICC 4475 & $83.72^{\mathrm{a}}$ \\
\hline ICC 12004 & $51.87^{\mathrm{b}}$ & ILC 605 & $81.72^{\mathrm{a}}$ \\
\hline ILC 8068 & $45.99^{c}$ & & \\
\hline ICC 4475 & $43.84^{\mathrm{c}}$ & ILC 8068 & $52.46^{\mathrm{b}}$ \\
\hline ILC 200 & $41.26^{\mathrm{cd}}$ & ILC 7374 & $45.47^{\mathrm{bc}}$ \\
\hline ILC 7374 & $36.05^{\mathrm{d}}$ & ILC 7795 & $38.78^{\mathrm{c}}$ \\
\hline ILC 7795 & $33.00^{\mathrm{d}}$ & ILC 200 & $38.75^{\mathrm{c}}$ \\
\hline
\end{tabular}

$\overline{\mathrm{a}, \mathrm{b}, \mathrm{c}, \mathrm{d}}$ means followed by the same letter are not significant based on duncan test at 0.05 probability level.

TABLE 5: Analysis of variance of combining ability of F1 at seedling stage.

\begin{tabular}{lccccc}
\hline Source of variation & D.F. & S.S. & M.S. & $F$ & Signification \\
\hline GCA & 7 & 5754.3 & 822.04 & 34.50 & 1.47 \\
SCA & 28 & 666.4 & 23.80 & 16.11 & n.s. \\
Error & 49 & & & \\
\hline
\end{tabular}

** significant at 0.01 probability level.

TABLE 6: Analysis of variance of combining ability of F2 at seedling stage.

\begin{tabular}{|c|c|c|c|c|c|}
\hline Source of variation & D.F. & S.S. & M.S. & $F$ & Signification \\
\hline GCA & 7 & 5515.2 & 787.89 & 37.32 & $* *$ \\
\hline SCA & 28 & 591.1 & 21.11 & 1.31 & n.s. \\
\hline Error & 49 & & 16.11 & & \\
\hline
\end{tabular}

${ }^{* *}$ significant at 0.01 probability level.

TABLE 7: GCA value of 8 parents at the seedling stage of F1.

\begin{tabular}{lcccc}
\hline Parents & \multicolumn{2}{c}{ F1 } & \multicolumn{2}{c}{ F2 } \\
& GCA & Pr. & GCA & Pr. \\
\hline ILC 263 & 17.34 & $<0.001$ & 15.87 & $<0.001$ \\
ILC 605 & 9.14 & $<0.001$ & 11.33 & $<0.001$ \\
ILC 200 & -5.77 & $<0.001$ & -6.4 & $<0.001$ \\
ILC 7374 & -8.29 & $<0.001$ & -7.81 & $<0.001$ \\
ILC 7795 & -8.85 & $<0.001$ & -7.83 & $<0.001$ \\
ILC 8068 & -2.81 & $0.1-0.05$ & -1.52 & $0.5-0.2$ \\
ICC 4475 & -1.57 & $0.5-0.2$ & -0.97 & 0.5 \\
ICC 12004 & 0.81 & $0.8-0.5$ & -3.04 & $0.05-.0 .2$ \\
\hline
\end{tabular}

generations. This group includes parents which are the most susceptible: ILC 263, ICC 4475, ICC 12004, and ILC 605.

(ii) A second group is composed of a single breeding line: ILC 8068, moderately susceptible with an estimated value of GCA negative with -3.55 in F1 and -3.90 in F2; however these values are not significant.

(iii) The last group of three resistant breeding lines, ILC 200, ILC 7374, and ILC 7795, highlights an estimated
TABLE 8: Variance of combining ability estimates and component of variation.

\begin{tabular}{lcccc}
\hline \multirow{2}{*}{ Variances } & \multicolumn{2}{c}{ Seedling stage } & \multicolumn{2}{c}{ Adult stage } \\
& F1 & F2 & F1 & F2 \\
\hline GCA & 79.82 & 76.68 & 94.23 & 72.48 \\
SCA & 7.68 & 4.99 & 26.47 & 25.51 \\
A & 159.6 & 153.4 & 188.5 & 145 \\
D & 7.68 & 4.99 & 26.47 & 25.51 \\
\hline
\end{tabular}

TABLE 9: Other genetic components.

\begin{tabular}{lcccc}
\hline Component & \multicolumn{2}{c}{ Seedling stage } & \multicolumn{2}{c}{ Adult stage } \\
\hline$(\mathrm{H} 1 / \mathrm{D})^{1 / 2}$ & 0.36 & 0.30 & 0.45 & 0.45 \\
$\left\{(4 \mathrm{DH} 1)^{1 / 2}+\mathrm{F}\right\} /\left\{(4 \mathrm{DH} 1)^{1 / 2}-\mathrm{F}\right\}$ & 0.77 & 0.52 & 0.16 & 2.77 \\
$1 / 4 \mathrm{H} 2 / \mathrm{H} 1$ & 0.17 & 0.15 & 0.22 & 0.19 \\
Correlation coefficient & 0.41 & 0.39 & -0.95 & -0.91 \\
$\mathrm{~h}_{2} / \mathrm{H} 2(\mathrm{k})$ & -0.20 & -2.89 & 1.71 & 1.60 \\
$\mathrm{~h}_{2} \mathrm{~s}$ & 0.87 & 0.71 & 0.84 & 0.90 \\
$\mathrm{~h}_{2} \mathrm{l}$ & 0.91 & - & 0.94 & \\
\hline
\end{tabular}

value of GCA strong and different of zero but negative and varies from 8.99 to 12.44 for $\mathrm{F} 1$ and 7.51 to 10.28 
TABle 10: Analysis of estimates of combining ability at adult stage.

\begin{tabular}{|c|c|c|c|c|c|c|c|c|c|c|}
\hline \multirow{2}{*}{ Source of variation } & \multicolumn{5}{|c|}{ F1 } & \multicolumn{5}{|c|}{$\mathrm{F} 2$} \\
\hline & D.F. & S.S. & M.S. & $F$ & Sign & D.F. & S.S. & M.S. & $F$ & Sign \\
\hline GCA & 7 & 6871 & 981.59 & 25.02 & $* * *$ & 7 & 5341 & 763.06 & 19.94 & $* *$ \\
\hline SCA & 28 & 1099 & 39.24 & 3.07 & $* *$ & 28 & 1072 & 38.28 & 3.00 & $* *$ \\
\hline Error & 49 & & 12.76 & & & 49 & & 12.76 & & \\
\hline
\end{tabular}

**,*** significant at 0.01 and 0.001 probability level, respectively.

TABLE 11: GCA value of 8 parents at the adult stage.

\begin{tabular}{lcccc}
\hline Parents & \multicolumn{2}{c}{ F1 } & \multicolumn{2}{c}{ F2 } \\
& GCA & Pr. & GCA & PR \\
\hline ILC 263 & 9.95 & $<0.001$ & 8.87 & $<0.001$ \\
ILC 605 & 9.52 & $<0.001$ & 5.87 & 0.002 \\
ILC 200 & -8.99 & $<0.001$ & -9.98 & $<0.001$ \\
ILC 7374 & -10.69 & $<0.001$ & -7.51 & $<0.001$ \\
ILC 7795 & -12.44 & $<0.001$ & -10.28 & 0.001 \\
ILC 8068 & -3.55 & $0.1-0.05$ & -3.90 & $0.05-0.02$ \\
ICC 4475 & 9.52 & $<0.001$ & 9.04 & $0.5-0.2$ \\
ICC 12004 & 9.44 & $<0.001$ & 7.90 & $0.8-0.5$ \\
\hline
\end{tabular}

for F2. However the specific combining ability (CSA) has a minor effect but significant for both generations (Table 10).

The variance of the GCA $\left(\alpha^{2} \mathrm{~g}\right)$ in F1 is greater than that of the $\mathrm{F} 2$, while the variance of the ASC $\left(\alpha^{2} \mathrm{~S}\right)$ is identical (Table 8$)$. The ratio of additive/dominance is 3 to 1 in $\mathrm{F} 1$ and 2.85 to 1 in F2, which shows the predominance of additive effect versus dominance. Estimates of heritability are very high which were also obtained here. The narrow sense heritability is of 0.84 in $\mathrm{F} 1$ and 0.90 in F2, while the broad sense heritability in F1 is slightly higher and is equal to 0.94 (Table 9).

3.1.3. Genetic Components. For seedling stage, the additive effect (D) has high value and is significantly different from zero for the two generations, which confirms the importance of additive component of $A$. rabiei resistance (Table 12). Other effects were not significant except for the effect of dominance of heterozygous loci $h_{2}$ which is significant in F2 because of the relatively high standard errors. The dominance of the character is incomplete because $\mathrm{H} 1$ is less than $\mathrm{D}$. The negative sign of $\mathrm{F}$ for the two generations indicates that there are much more recessive alleles than dominant alleles that affect resistance to the disease, regardless of whether they have a negative or positive effect. It is confirmed that the average degree of dominance at each locus $(\mathrm{H1} / \mathrm{D})^{1 / 2}$ is small and positive (Table 9). The asymmetry of the gene frequency $(\mathrm{H} 2<\mathrm{H} 1)$ is not too large $(\mathrm{H} 2 / 4 \mathrm{H} 1=0.17$ in $\mathrm{F} 1$ and 0.15 in F2) which denotes that these genes were not asymmetrically distributed among the parental genotypes. The number of effective factors that determine the resistance to disease is between 1 and 3 for the two generations $(k=-0.20$ in F1 and -2.89 in F2) (Table 12). For this diallel there is a weak correlation at seedling stage $(r=0.41$ for F1 and 0.39 for
F2) between the parental measures and values of $\mathrm{Wr}+\mathrm{Vr}$ (Table 9).

For adult stage, all the genetic components of variance are significantly different from zero (Table 12). Environmental variance is very small relative to genetic variation. The additive effects (D) have the highest value, which indicates the importance of this component for resistance to A. rabiei. $\mathrm{F}$ is positive in both generations and shows that there are more dominant than recessive alleles that control the plant reaction to the pathogen, regardless of whether they have an effect positive or negative on the character. This is confirmed by the ratio $\left\{(4 \mathrm{DH} 1)^{1 / 2}+\mathrm{F}\right\} /\left\{(4 \mathrm{DH} 1)^{1 / 2}-\mathrm{F}\right\}$ which is equal to 0.16 for the F1 and 2.77 for the F2 (Table 9). In conditions of equality this ratio must be equal to 1 [9]. For dominance effects, $\mathrm{H} 1$ and $\mathrm{H} 2$ are much higher in $\mathrm{F} 2$ than in F1, which is explained by the fact that, after each generation, heterozygosis is halved (Table 12). $\mathrm{H} 1$ is greater than $\mathrm{H} 2$ in both generations, which is not in contradiction with our results since these parameters are equal in situation of equal number of dominant and recessive genes. This reveals an asymmetry in the distribution of favorable and nonfavorable alleles in the parents, a situation already confirmed above by the level of signification of F. (H1/D) $)^{1 / 2}$ is equal to 0.45 , which confirms the existence of partial or incomplete dominance of the material tested in this diallel (Table 9). Indeed the ratio $\mathrm{H} 1 / \mathrm{D}$ estimates the average degree of dominance in the situation where there are in the parents equal proportions of favorable and unfavorable alleles; this ratio tends to be in favor of genes or groups of genes in linkage, having large effects. With partial average dominance, the ratio H1/D has a value between 0 and 1 [10]. The square root of the same parameter gives the average degree of dominance at each locus. It has the advantage of not being disturbed either by the correlations between genes or by the multiallelism. Insofar as it gets closer to $0.5(0.45)$, the mean degree of dominance is intermediate. The value of $\mathrm{H} 2 / 4 \mathrm{H} 1$ is 0.22 for F1 and 0.19 for F2 (Table 9). This ratio is a measure of asymmetry but concerns only loci showing dominance. This value gives an indication of the average frequency of positive allele (susceptibility) compared with negative alleles (resistance) for the parent. We can say that the positive alleles and the negatives are not evenly distributed, although the difference is not great because these two values are slightly below the maximum value which is equal to 0.25 when $u=v=0.5 . \mathrm{H} 2$ is positive in the two generations which shows that dominant genes are acting in their majority mostly towards the susceptibility. The ratio $\mathrm{h} 2 / \mathrm{H} 2$ gives an estimate of the minimum number of genes $(k)$ with a certain degree of dominance which controls the character, probably 
TABLE 12: Genetic components.

\begin{tabular}{lcccc}
\hline Component & \multicolumn{2}{c}{ Seedling stage } & \multicolumn{2}{c}{ Adult stage } \\
& F1 & F2 & F1 & $458.80 \pm 9.75$ \\
$\mathrm{D}$ & $291.80 \pm 10.54$ & $291.80 \pm 11.32$ & $458.80 \pm 13.64$ & $377.70 \pm 89.66$ \\
$\mathrm{H} 1$ & $39.61 \pm 24.24$ & $106.00 \pm 104.1$ & $94.20 \pm 31.37$ & $298.20 \pm 78.01$ \\
$\mathrm{H} 2$ & $27.31 \pm 40.71$ & $66.16 \pm 90.56$ & $84.07 \pm 27.29$ & $477.40 \pm 52.31$ \\
$\mathrm{~h}_{2}$ & $-5.58 \pm 14.14$ & $-191.50 \pm 60.73$ & $97.82 \pm 32.24$ & $195.60 \pm 45.98$ \\
$\mathrm{~F}$ & $-27.43 \pm 24.91$ & $-54.86 \pm 53.37$ & $12.76 \pm 4.58$ & $12.76 \pm 3.25$ \\
$\mathrm{E}$ & $16.11 \pm 3.51$ & $16.11 \pm 3.77$ &
\end{tabular}

D: additive genetic variance, $\mathrm{H} 1$ and $\mathrm{H} 2$ : dominance genetic variance and corrected dominance genetic variance, $\mathrm{F}$ : product of additive by dominance, $\mathrm{h}_{2}$ : dominance effect, and E: environmental variance.

the susceptibility. For the two generations the number of genes is a minimum of two $(k=1.71$ and 1.60 , resp.). Indeed, according to Hayman [8] and Jana and Seyffert [9], this ratio underestimates the number of factors involved in the control of the character.

The coefficients of correlation between the parental measures $(\mathrm{Wr}+\mathrm{Vr})$ for $\mathrm{F} 1$ and F2 are -0.94 and -0.91 , respectively. They indicate that there is a very high correlation between the dominant genes and susceptibility to A. rabiei among the material studied and confirm that dominance is unidirectional. So, when the coefficients of determination are close to unity, it indicates a sharp decline of regression yr on $(\mathrm{Wr}+\mathrm{Vr})$ that can make predictions about the parents most dominants and most recessives.

The main objective of this study is to analyze the components of variation of resistance to A. rabiei of eight chickpea lines at two different stages of the plant, seedling and adult stages. In the absence of epistasis, the diallel gives extensive information on genetic constitution of parents of the character studied.

The predominance of the additive effect is demonstrated for both stages of the plant $[11,12]$. This could allow breeders to use this important feature in their improvement program of quantitative resistance to blight.

The number of dominant and recessive genes is uneven in the parents as has been shown by the values $\mathrm{H} 1$ and $\mathrm{H} 2$. There exist in the parents recessive alleles that express themselves mainly in the seedling stage, while it is the dominant alleles that express themselves in the adult stage. This is confirmed by the value $h^{2}$ which is negative in the seedling stage and positive in the adult stage (Table 12). Also the mean degree of dominance $(\mathrm{H} 1 / \mathrm{D})^{1 / 2}$ is relatively low in the seedling stage $(0.30)$ and a little higher in the adult stage (0.45). This ratio is not affected by the presence of linkage or multiallelism, but it is by the presence of epistasis [9]. The asymmetry of favorable and unfavorable alleles is a little larger in seedling stage than the adult stage. The proportion of recessive genes relative to dominant genes is bigger in the seedling stage, but the reverse is observed in the adult stage. prediction limit of selection at the seedling stage is apparently not possible, but it is in the adult stage (coefficient of correlation $=-0.90$ ).

The value of an individual, as a parent, is dependent on the following:

(i) the qualities of gametic means linked to its own structure; (ii) the qualities of combination with a partner related to a success of gametic meetings. These gametic quality means are characterized by the general combining ability (GCA) and are due to the effects of additive which is transmitted with the linkage. Qualities of combination with a partner characterize the specific combining ability (CSA) and are related to dominance and epistasis and are completely conditioned by the overall structure of the individual [13]. For both stages, the GCA is greater than the CSA which is not significantly different from zero for the seedling stage and very low in adult stage. This reduced the value which is not significant and is probably an indication of small part due to the dominance and to the limited epistatic genes effects [14].

The importance of the additive effect noted above for the two stages is also translated by the ratio of variance $\left(\alpha^{2} \mathrm{~g} / \alpha^{2} \mathrm{~s}\right)$ which is very high and the additive component $\left(\alpha^{2} \mathrm{~A}\right)$ which is higher than the dominance $\left(\alpha^{2} \mathrm{D}\right)$ with high heritability. We can therefore predict the performance of crosses from the GCA of parents [15]. Additive gene effects and high broad sense heritability showed possible selection for this trait in early generations.

To this end, three lines, ILC 200, ILC 7374, and ILC 7795, can be used as breed to improve the resistance of chickpea to race 4 of $A$. rabiei, for both the seedling and the adult stage [6]. Another parent ILC 8068 seems to be interesting to the adult stage. Also, the results in Table 12 indicate that this trait was greatly influenced by the environment.

\section{Conclusion}

The present investigation was undertaken to study combining ability and the genetic components for blight in chickpea (Cicer arietinum L.); the common results for the genetic analysis reveal the following important points.

(i) Genetic determinism for A. rabiei resistance is oligogenic if not polygenic (the number of genes is equal or greater than two).

(ii) The main effect of genes is additive, the AGC is very high, and the heritability is strong. However, we noted some cross effects of interaction of additive-dominance and dominance-dominance for the seedling stage. 
(iii) The nature of the dominance is incomplete or partial.

(iv) The genes that express themselves in the seedling stage are not probably those who express themselves in the adult stage.

(v) In the seedling stage the dominant and recessive genes determine the resistance, whereas in the adult stage it is the lines that the allelic composition which is principally dominant that are very susceptible.

\section{Conflict of Interests}

The authors, and on behalf of them Dr. Mohamed Labdi, declare that they do not have any conflict of interests regarding the publication of this paper.

\section{References}

[1] S. Maiden, "Seed borne disease of chickpea in Turkey," Journal of Turkish Phytopathology, vol. 16, no. 1, pp. 1-8, 1987.

[2] W. J. Kaiser, "Inter- and intranational spread of Ascochyta pathogens of chickpea, faba bean, and lentil," Canadian Journal of Plant Pathology, vol. 19, no. 2, pp. 215-224, 1997.

[3] S. K. Tewari and M. P. Pandey, "Genetics of resistance to Ascochyta blight in chickpea (Cicer arietinum L.)," Euphytica, vol. 35, no. 1, pp. 211-215, 1986.

[4] M. Labdi, R. S. Malhotra, I. E. Benzohra, and M. Imtiaz, "Inheritance of resistance to Ascochyta rabiei in 15 chickpea germplasm accessions," Plant Breeding, vol. 132, no. 2, pp. 197-199, 2013.

[5] H. Flandez-Galvez, P. K. Ades, R. Ford, E. C. K. Pang, and P. W. J. Taylor, "QTL analysis for ascochyta blight resistance in an intraspecific population of chickpea (Cicer arietinum L.)," Theoretical and Applied Genetics, vol. 107, no. 7, pp. 1257-1265, 2003.

[6] Q. Ali, N. Javed, A. Ahmad et al., "Development of Ascochyta blight (Ascochyta rabiei Pass. Labr.) resistant chickpea (Cicer arietinum) genotype," African Journal of Bacteriology Research, vol. 3, no. 4, pp. 69-76, 2011.

[7] N. V. Reddy, K. B. Singh, and Y. L. Nene, "Screening techniques of Ascochyta blight of chickpea," in Workshop on Ascochyta Blight Winter Sowing Chickpea, M. C. Saxena and K. B. Singh, Eds., pp. 45-53, ICARDA, Aleppo, Syria, 1984.

[8] B. I. Hayman, "The theory and analysis of diallel cross," Genetics, vol. 39, pp. 789-809, 1954.

[9] S. Jana and W. Seyffert, "Simulation of quantitative characters by genes with biochemically definable action," Theoretical and Applied Genetics, vol. 42, no. 1, pp. 16-24, 1972.

[10] D. W. Crumpacker and R. W. Allard, "A diallel cross analysis of heading date in wheat," Hilgardia, vol. 32, no. 6, pp. 275-318, 1962.

[11] R. A. Vieira, C. A. Scapim, L. M. Moterle, D. J. Tessmann, T. V. Conrado, and A. T. Amaral Jr., "Diallel analysis of leaf disease resistance in inbred Brazilian popcorn cultivars," Genetics and Molecular Research, vol. 8, no. 4, pp. 1427-1436, 2009.

[12] J.-B. N. Tchiagam, J. M. Bell, D. F. Ngakeu, N. Y. Njintang, and E. Youmbi, "Diallel analysis of cowpea (Vigna unguiculata (L.) Walp.) for some physical properties of seed under the Sudanoguinean conditions," Agriculture and Biology Journal of North America, vol. 2, no. 4, pp. 698-707, 2011.

[13] Y. Demarly, "Commentaires sur les aptitudes à la combinaison," Annales de l'Amelioration des Plantes, vol. 22, pp. 187-200, 1972.
[14] M. van Ginkel and A. L. Scharen, "Diallel analysis of resistance to Septoria tritici isolates in durum wheat," Euphytica, vol. 38, no. 1, pp. 31-37, 1988.

[15] A. Gallais, "Sur la signification de l'aptitude générale à la combinaison," Annales de l’Amélioration des Plantes, vol. 26, no. 1, pp. $1-13,1976$. 


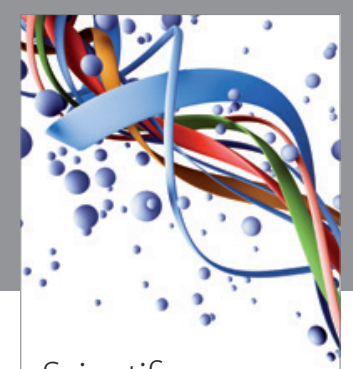

Scientifica
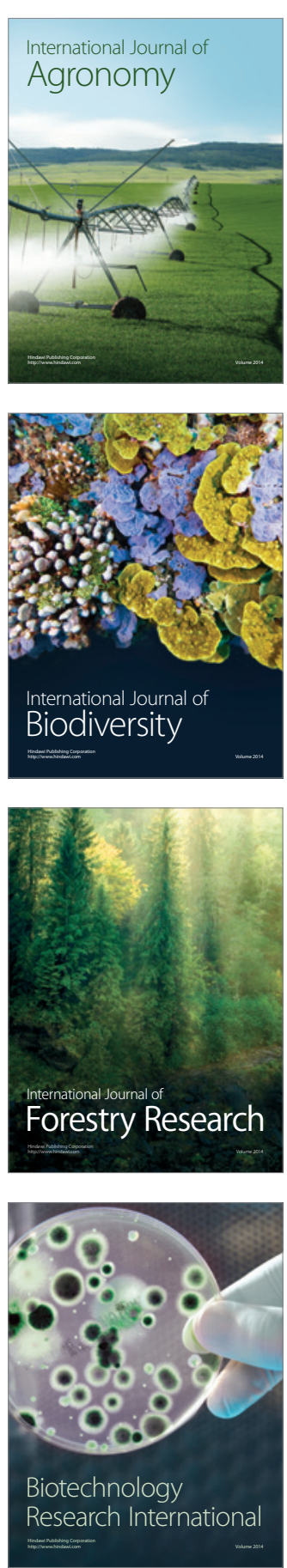
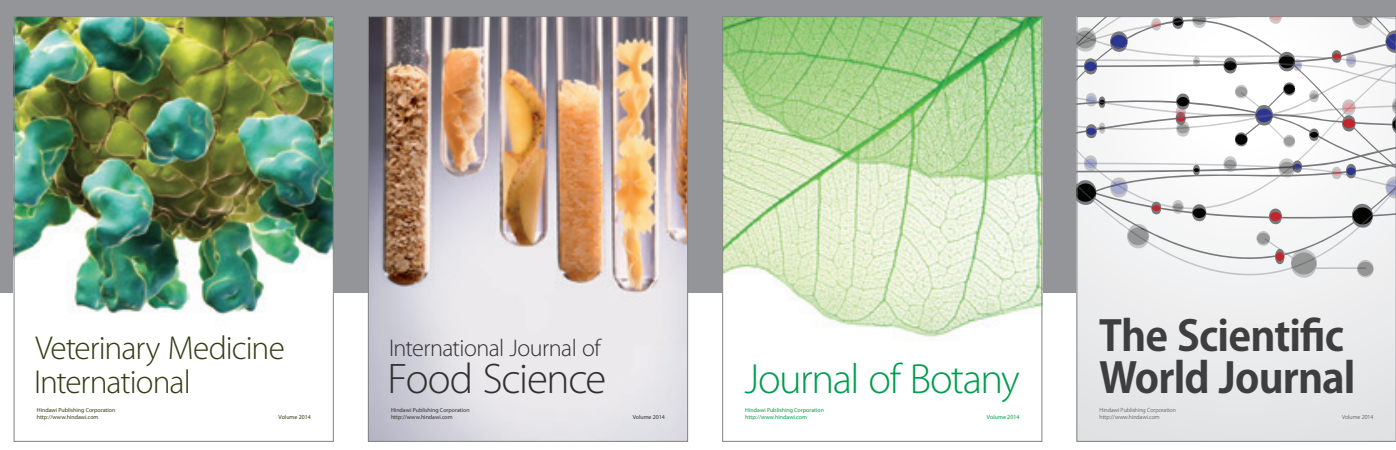

The Scientific World Journal
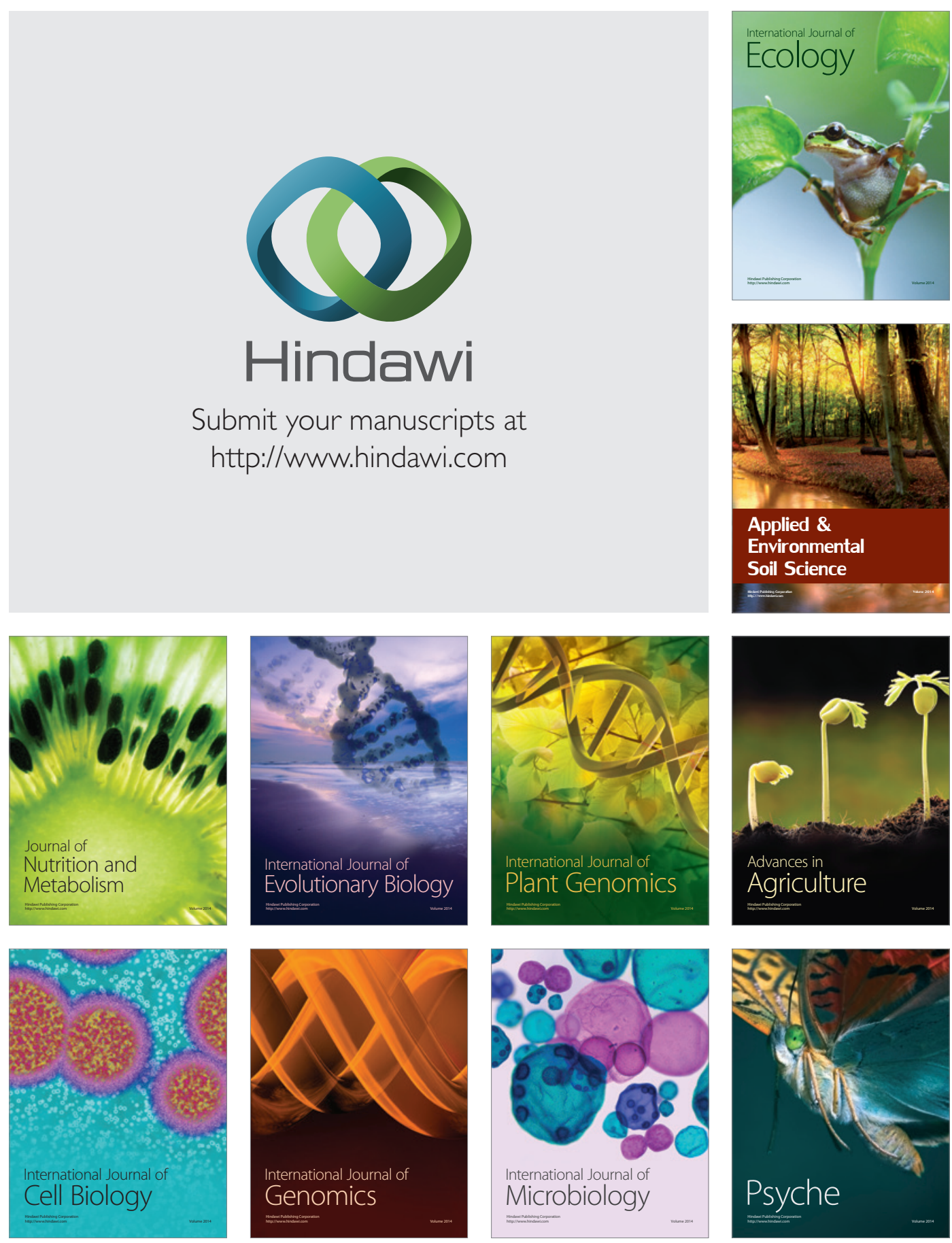